\title{
Spontaneous pneumomediastinum - a rare cause of chest pain and dyspnoe in children
}

\author{
Marcin Mikoś \\ Department of Pneumonology, Pediatric Allergy and Clinical \\ Immunology, Poznan University of Medical Sciences, Poland \\ (D) https://orcid.org/0000-0003-2792-3764 \\ Corresponding author: eedris888@yahoo.com \\ Katarzyna Jończyk-Potoczna \\ Department of Pediatric Radiology, Poznan \\ University of Medical Sciences, Poland \\ (iD) https://orcid.org/0000-0002-9412-8931

\section{Paulina Sobkowiak} \\ Department of Pneumonology, Pediatric Allergy and Clinical \\ Immunology, Poznan University of Medical Sciences, Poland \\ (iD) https://orcid.org/0000-0003-2737-8946
}

\section{Anna Bręborowicz}

Department of Pneumonology, Pediatric Allergy and Clinical Immunology, Poznan University of Medical Sciences, Poland

(iD) https://orcid.org/0000-0001-7811-7565

\section{Edyta Nagła}

Department of Pulmonology, Pediatric Allergy and Clinical Immunology, Poznan University of Medical Sciences, Poland (iD) -

\section{Magdalena Mrówczyńska}

Department of Pneumonology, Pediatric Allergy and Clinical Immunology, Poznan University of Medical Sciences, Poland

\author{
Irena Wojsyk-Banaszak \\ Poznan University of Medical Sciences, Poland \\ (iD) https://orcid.org/0000-0001-6724-1499
}

DOI: https://doi.org/10.20883/medical.e570

Keywords: sponteneous pneumomediastinum, chest pain, dyspnoe, children

Published: 2021-12-29

How to Cite: Mikoś M, Jończyk-Potoczna K, Sobkowiak $P$, Bręborowicz A, Nagła E, Mrówczyńska M, Wojsyk-Banaszak I. Spontaneous pneumomediastinum - a rare cause of chest pain and dyspnoe in children. Journal of Medical Science. 2021;90(4);e570. doi:10.20883/medical.e570.

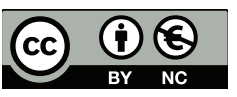

(c) 2021 by the author(s). This is an open access article distributed under the terms and conditions of the Creative Commons Attribution (CC BY-NC) licencse. Published by Poznan University of Medical Sciences

\section{ABSTRACT}

Introduction. Spontaneous pneumomediastinum is a very rare condition in children. Nevertheless it should be considered in the differential diagnosis in patients who present with chest pain and dyspnoe.

Aim. The aim of our study was to describe clinical presentation, management and outcomes of the paediatric patients with spontaneous pneumomediastinum

Material and Methods. This was a retrospective analysis of the charts of all the patients who were admitted to the Department of Pneumonology, Paediatric Allergy and Clinical Immunology in a ten year period from 01.01.2011 till 31.12.2020 in whom spontaneous pneumomediastinum was diagnosed.

Results. There were 11 children ( 7 females) with spontaneous pneumomediastinum. The median age of the children was 11 years (range 3 to 17.5 years). Most of the children presented to the hospital with chest pain, three children complained of the neck swelling and four children developed dyspnoe. Three children with the primary spontaneous pneumomediastinum had a history of physical exercise prior to the onset of symptoms. The secondary spontaneous pneumomediastinum occurred in two children with asthma and 4 children with pneumonia. Genetic material of human Bocavirus was identified in 3 cases. In $81.8 \%$ of children pneumomediastinum was accompanied by subcutaneous emphysema and in one case, in a child with severe pneumonia and respiratory insufficiency caused by Bocavirus with pneumorrhachis. In 10 children 
computed tomography was performed, bronchoscopy in 4 and esophagoscopy in two children. There was no evidence of esophageal rupture or bronchial tree rupture in any of our patients. Three children with pneumonia and pneumomediastinum developed respiratory insufficiency, two of these were treated with mechanical ventilation and one with High Flow Nasal Cannula oxygen therapy. All the children received oxygen. In one child surgical procedure was performed and the drain was inserted into mediastinal space in order to decompress it. Outcome was favourable in all children. Mean time to recovery was $10.6 \pm 1.2$ days. There was no recurrence of symptoms in any of our patients.

Conclusions. Spontaneous pneumomediastinum in most cases is a benign condition, sporadically however it may progress rapidly, leading to respiratory insufficiency and warrant invasive management.

\section{Introduction}

Spontaneous pneumomediastinum is a rare condition in children defined as an accumulation of air in the mediastinal cavity that is not caused by trauma or iatrogenic causes such as positive pressure ventilation or intrathoracic surgical procedures. Spontaneous pneumomediastinum can be further divided into primary without any underlying condition or secondary which occurs in children with pulmonary conditions such as asthma or respiratory infections [1]. Primary spontaneous pneumomediastinum might be triggered by the activities leading to sudden increase in intrathoracic pressure like strenuous physical exercise, coughing, vomiting [2]. These would cause the rupture of the alveoli, and the air released from damaged alveoli in the pulmonary interstitium reaches mediastinal space along the perivascular and peribronchial sheaths [3]. The incidence varies widely from 1 in 800 to 1 in 42000 patients presenting to emergency departments [4]. The course of the primary spontaneous pneumomediastinum is usually benign, although in many patients thorough diagnostic procedures including computed tomography scans, bronchoscopy and esophagoscopy are performed in order to exclude underlying pathologies like esophageal or bronchial rupture and avoid possible severe complications.

\section{Aim}

The aim of our study was to describe clinical presentation, management and outcomes of the paediatric patients with spontaneous pneumomediastinum.

\section{Materials and methods}

This was a retrospective single institution study. We reviewed the charts of all the patients who were admitted to the Department of Pediatric Pneumonology, Allergy and Clinical Immunology in a ten year period from 01.01.2011 till 31.12.2020 in whom spontaneous pneumomediastinum was diagnosed. Cases of traumatic or iatrogenic pneumomediastinum were excluded from our analysis. The diagnosis was based on radiological tests results (conventional $x$-rays, computed tomography or both). We collected data including anthropometric parameters, present comorbidities, clinical presentation, diagnostic studies (microbiology, molecular testing) test results, treatment regimens, length of hospital stay as well as presence and type of complications and outcome from the electronic patients records.

\section{Results}

\section{Patients' characteristic}

There were 11 children with spontaneous pneumomediastinum in the given period, 7 of whom were female. 7 children were inpatients and four were transferred from other hospitals. The median age of the children was 11 years (range 3 to 17.5 years). The clinical characteristic of our patients is given in the table 1. The incidence of pneumomediastinum calculated as the percentage of all emergency admissions due to respiratory causes was $0.0009 \%$ or 1 in 1145 admissions. Most of the children presented to the hospital with chest pain, three children complained of the neck swelling and four children developed dyspnoe in the course of pneumonia. The mean time from the onset of symptoms to the hospi- 


\begin{tabular}{lc} 
Sex F/M & $7 / 4$ \\
\hline $\begin{array}{l}\text { Age [years] (median) } \\
\text { Primary spontaneous } \\
\text { pneumomediastinum }\end{array}$ & $11(3-17.5)$ \\
\hline $\begin{array}{l}\text { Secondary spontaneous } \\
\text { pneumomediastinum }\end{array}$ & $5(45.4 \%)$ \\
\hline \multicolumn{2}{c}{ Symptoms } \\
\hline Chest pain & $7(54.5 \%)$ \\
\hline Dyspnoe & $9(81.8 \%)$ \\
\hline Cough & $8(72.7 \%)$ \\
\hline Neck pain & $4(36.4 \%)$ \\
\hline Neck edema & $3(27.3 \%)$ \\
\hline Tachycardia & $8(72.1 \%)$ \\
\hline Tachypnoe & $6(54.5 \%)$ \\
\hline Fever & $5(45.4 \%)$ \\
\hline Abdominal pain & $1(9.1 \%)$ \\
\hline Vomiting & $1(9.1 \%)$ \\
\hline Coexisting pneumothorax & $5(45.4 \%)$ \\
\hline Subcutaneous emphysema & $9(81.8 \%)$
\end{tabular}

tal admission was $2.6 \pm 2.1$ days, most presented to the emergency department during the first 24 hours of their illness. Three children with the primary spontaneous pneumomediastinum had a history of physical exercise in the course of several days preceding the onset of symptoms. The secondary spontaneous pneumomediastinum occurred in two children with asthma and 4 children with pneumonia. One patient with asthma had upper respiratory tract infection that had triggered asthma exacerbation. The etiology of pneumonia was confirmed in all the cases: we isolated Staphylococcus aureus in one case, and identified genetic material of Parainfluenzae virus type 3 in 2 cases and human Bocavirus in 3 cases (in one case genetic material of both viruses was present). In $81.8 \%$ of children pneumomediastinum was accompanied by subcutaneous emphysema and in one case, in a child with severe pneumonia and respiratory insufficiency caused by Bocavirus with pneumorrhachis. One adolescent was an active tobacco smoker who admitted to smoking 3-4 cigarettes per day.

\section{Management}

In 10 children computed tomography was performed, bronchoscopy in 4 and esophagoscopy in two children. There was no evidence of esophageal rupture or bronchial tree rupture in any of our patients. Three children with pneumonia and pneumomediastinum developed respiratory insufficiency, two of these were treated with mechanical ventilation and one with High Flow Nasal Cannula oxygen therapy. Pneumomediastinum was present in these children prior to the initiation of ventilatory support. All the children received oxygen therapy. In one child surgical procedure was performed and the drain was inserted into mediastinal space in order to decompress it (Figure 1). Outcome was favour-

Table 1. Clinical characteristic of patients with spontaneous pneumomediastinum

\begin{tabular}{|c|c|c|c|c|c|c|c|c|c|c|c|c|}
\hline 营 & 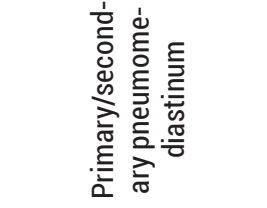 & 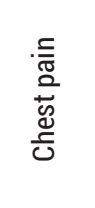 & $\begin{array}{l}\text { ज्ञ } \\
\text { ত̃ }\end{array}$ & $\begin{array}{l}\text { ठ } \\
\frac{0}{0} \\
\frac{0}{0}\end{array}$ & 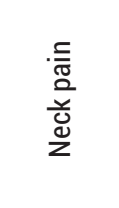 & 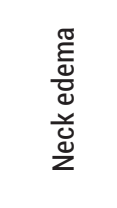 & 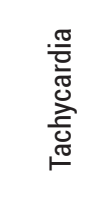 & 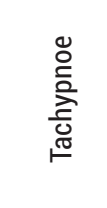 & ¿্ষ & 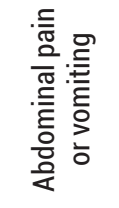 & 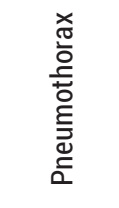 & 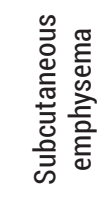 \\
\hline 1 & Primary & + & - & + & + & + & - & + & - & - & - & + \\
\hline 2 & Primary & + & - & + & + & - & + & + & - & - & + & + \\
\hline 3 & Primary & + & - & - & + & + & + & - & - & - & + & + \\
\hline 4 & Primary & + & + & + & - & - & + & + & - & - & + & - \\
\hline 5 & Primary & + & + & - & + & - & - & - & - & - & - & + \\
\hline 6 & $\begin{array}{l}\text { Secondary } \\
\text { (pneumonia) }\end{array}$ & - & + & + & - & - & + & + & + & + & + & + \\
\hline 7 & $\begin{array}{l}\text { Secondary } \\
\text { (pneumonia) }\end{array}$ & - & + & + & - & - & + & + & + & - & + & + \\
\hline 8 & Secondary (asthma) & + & + & + & - & + & + & - & - & + & - & + \\
\hline 9 & $\begin{array}{l}\text { Secondary } \\
\text { (pneumonia) }\end{array}$ & + & + & + & - & - & + & + & + & - & - & + \\
\hline 10 & Secondary (asthma) & - & + & + & - & - & - & - & + & - & - & - \\
\hline 11 & $\begin{array}{l}\text { Secondary } \\
\text { (pneumonia) }\end{array}$ & - & + & + & - & - & + & - & + & - & - & + \\
\hline Sum (\%) & $5(45.4 \%) / 6(54.5 \%)$ & $7(63.6)$ & $8(72.7)$ & $9(81.8)$ & $4(36.4)$ & $3(27.3)$ & $8(72.7)$ & $6(54.5)$ & $5(45.4)$ & $2(18.2)$ & $5(54.5)$ & $9(81.8)$ \\
\hline
\end{tabular}


able in all children. Mean time to recovery was $10.6 \pm 1.2$ days. In most children it was less than a week. Since recovery was defined as no residual pneumomediastinum on radiological exam this might be a bit longer than the actual recovery time, since we did not perform x-ray or CT every day. Mean length of hospital stay was $15.3 \pm 5.6$ days. There was no recurrence of symptoms in any of our patients.

\section{Discussion}

Spontaneous pneumomediastinum (SP) is a rare medical entity in paediatric patients, although probably it remains underdiagnosed in many cases [4]. It should be taken into consideration in children and adolescents with sudden onset chest pain or dyspnoea as well as subcutaneous emphysema. There are only few retrospective studies and several case reports on the presentation and management of SP in children [1,2,5-9].

Most cases of secondary SP developed in the course of respiratory tract infection, frequently of viral etiology. Emiralioglu and colleagues described pneumomediastinum in the course of rhinovirus, human bocavirus and respiratory syncytial virus infections [9]. Other authors reported influenza A (H1N1) and coronavirus infections complicated with SP $[7,10]$. In two cases pneumomediastinum was accompanied by pneumorrhachis as in one of our patients. Another cause of spontaneous pneumomediastinum, mainly in teenagers is asthma exacerbation [8]. Up to 40-50\% children and adolescents with SP were diagnosed with asthma $[6,11]$. SP may appear during the first asthma attack in a child with no previous diagnosis [8]. Despite the high numbers of asthmatic among patients with spontaneous pneumomediastinum, their clinical course does not differ from patients without asthma [6]. In our series two of the patients were asthmatics one of whom had upper airways infection. Choking events as well as foreign body aspiration, none of which did we observe in our case series have been reported as a frequent cause of pneumomediastinum, in up to $12.6 \%$ of subjects in a retrospective cohort from Hong-Kong [5]. There are also several reports of association of SP with inhaled tobacco smoke or illicit drugs $[7,8]$. Only one of our patients admitted to tobacco smoking and two reported a history of physical exercise before the episode.

Most patients with primary spontaneous pneumomediastinum present with chest pain, and subcutaneous emphysema - most frequently swelling of the neck while patients with secondary spontaneous pneumomediastinum are more likely to present with dyspnoe and cough $[2,6,8]$. The onset of pain is acute and it may radiate to the back, shoulders or neck $[4,12]$. Tachycardia, tachypnoea are also present in many patients, as well as hoarsness, difficulties in swallowing and rhinolalia (nasally sounding voice resulting from the presence of air in the soft palate). In $18 \%$ of the patients mediastinal crunch or crepitations synchronous with the heart beat ("Hamman's sign") can be appreciated on auscultation over the cardiac apex and the left sternal border [8, 12,13]. Abbas and colleagues suggest that this different presentation of patients with primary and secondary spontaneous pneumomediastinum may translate into different diagnostic approach, and may guide further decisions concerning diagnostic approach [2].

In many patients, especially treated in earlier years invasive diagnostic procedures (bronchoscopy and gastroscopy) were performed in the fear that SP might be caused by rupture in the airways or esophageal perforation potentially leading to mediastinitis. Fortunately no such findings were ever present in any of the studies performed and indeed the spontaneous rupture of the esophagus in children is extremely rare [14]. In a literature review of studies including both pediatric and adult patients Morgan and colleagues found that bronchoscopy was performed in $14.6 \%$ of patients and esophagogastroscopy in 13\% [15]. Similar results described Wong in his pediatric case series: esophagoscopy was performed in $13.8 \%$ of cases and revealed no abnormalities and bronchoscopy was performed in $27.6 \%$ of patients and found foreign body in 3 children younger than 6 years with no documented choking episodes [5]. Fitzwater and colleagues performed CT scans and contrast radiographic studies in $80 \%$ of their patients with spontaneous pneumomediastinum, yet in none of these children tests results revealed an abnormality that would influence further management [6]. In recent years, especially in the emergency department setting chest ultrasound is gaining an increasing importance in the 
evaluation of pneumomediastinum allowing to spare radiation [12].

Treatment is mostly conservative and comprises of bed rest, oxygen administration, management of underlying conditions including asthma or pneumonia. Kouritas and colleagues recommend oxygen therapy as it may increase gas absorption by six times, not all the authors however recommend this course of treatment advocating for further studies prior to such a recommendation is firmly instituted [4,12]. In a series of adult and pediatric patients, concomitantly with invasive diagnostic procedures aiming at excluding the possible source of mediastinitis in up to $43 \%$ of patients for the same reason broad spectrum antibiotics were instituted [15]. Invasive procedures in the management of spontaneous pneumomediastinum were reported extremely infrequently. Perna and colleagues reported on an adult patient who underwent thoracotomy for tension pneumomediastinum [16]. This was also a case in one of our patients with respiratory insufficiency in the course of pneumonia with rapidly progressing tension pneumothorax in whom chest tube into mediastinal cavity was inserted.

Fitzwater and colleagues based on their experience with the spontaneous pneumomediastinum in otherwise healthy children postulated that this group of patients can be safely treated on outpatient basis without hospital admission or any invasive diagnostic procedures [6]. Similar conclusions were published by Noorbakhsh and colleagues [1]. Both authors suggest an adoption of very conservative approach in children and adolescents with primary spontaneous pneumomediastinum. In children with underlying conditions these should be vigorously treated in order to avoid further complications.

Hospital stay in the described case series was 1-3 days $[1,6]$ which is much shorter than in our Department. This may be due to the fact that more than half of our patients had underlying conditions that influenced hospital stay and on the other hand our policy of not discharging children who remain symptomatic. Considering the safety of home observation of such patients such policy should change in the future.

The retrospective nature of the study as well as the small number of patients constitute its main limitations. Despite the small numbers our report shed some light on the possible causes of spontaneous pneumomedistinum in children, underlying the important role of viral infections especially human Bocaviruses. It is also worth stressing that spontaneous pneumomediastinum should be considered in every child presenting to emergency department with chest pain and / or dyspnoe. Spontaneous pneumomediastinum in most cases is a benign condition, sporadically however it may progress rapidly, leading to respiratory insufficiency and warrant invasive management.

\section{Acknowledgements}

Conflict of interest statement

The authors declare no conflict of interest.

\section{Funding sources}

There are no sources of funding to declare.

\section{References}

1. Noorbakhsh KA., Williams AE., Langham JJW., Wu L., Krafty RT., Furtado AD., Zuckerbraun NS., Manole MD. Management and outcomes of spontaneous pneumomediastinum in children. Pediatr Emerg Care 2019. doi: 10.1097/PEC.0000000000001895

2. Abbas PI., Akinkuotu AC., Peterson ML., Mazziotti MV. Spontaneous pneumomediastinum in the pediatrc patient. Am J Surg 2015;210:1031-1036

3. Vilaca AF., Reis AM., Vidal IM. The anatomical compartments and their connections as demonstrated by ectopic air. Insights Imaging 2013;4:759-772

4. Chalumeau M., Le Clainche L., Sayeg N., Sannier N., Michel JL., Marianowski R., Jouvet P., Scheinmann P., de Blic J. Spontaneous pneumomediastinum in children. Pediatric Pulmonol 2001; 31:67-75

5. Wong K., Wu HM., Lai SH., Chiu CY. Spontaneous pneumomediastinum. Analysis of 87 Pediatric Patients. Pediatr Emerg Care 2013;29:988-991

6. Fitzwater JW., Silva NN., Knight CG., Malvezzi L., Ramos-Irizarry C., Burnweit CA. Management of spontaneous pneumomediastinum in children. J Ped Surg 2015;50:983-986

7. Khan HH., Witkowski A., Clark JA., Mata A. A 17-year-old girl with a recent history of marijuana use presented with pneumomediastinum and pneumopericardium and tested positive for SARS-Cov-2 infection on hospital admission. Am J Case Rep 2021;22:e931800

8. Tortajada-Girbes M., Moreno-Prat M., Ainsa-Laguna D., Mas S. Spontaneous pneumomediastinum and subcutaneous emphysema as a complication of asthma in children: case report and literature review. Ther Adv Respir Dis 2016;10:402-409

9. Emiralioglu N., Ozcan HN., Oguz B., Yalcin E., Dogru D., Ozcelik U., Kiper N. Pneumomediastinum, pneumorrhachis and subcutaneous emphysema associated with viral infections: Report on three cases. Pediatrics Intern 2015;57:1038-1040 
10. Patel V., Raval G., Gavadia K. Pneumothorax, pneumomediastinum, subcutaneous emphysema and pneumorrhachis as complications of common flu. Am J Case Rep 2012;13:198-201

11. Chiu C., Wong K., Yao T., Huang J. Asthmatic versus non-asthmatic spontaneous pneumomediastinum in children. Asian Pac J Allergy Immunol 2005;23:19-22

12. Kouritas VK., Papagiannopoulos K., Lazaridis G., Baka S., Mpoukovinas I., Karavasilis V., Lampaki S. et al. Pneumomediastinum. J Thorac Dis 2015;7:S44-S49

13. Sahni S., Verma S., Grullon J., Esquire A., Patel P., Talwar A. Spontaneous pneumomediastinum: Time for consensus. North Am J Med Sci 2013;5:460-4
14. Antonis JH., Poeze M., Van Heurn LW. Boerhaave's syndrome in children; a case report and review of the literature. J Pediatr Surg 2006;41:1620-3

15. Morgan CT., Maloney JD., Decamp MM., McCarthy DP. A narrative review of primary spontaneous pneumomediastinum: a poorly understood and resource intensive problem. J Thorac Dis 2021;13:3721-3730

16. Perna V., Vila F., Guelbenzu JJ., Amat I. Pneumomediastinum: is this really a benign entity? When it can be considered as spontaneous? Our experience in 47 adult patients. Eur $\mathrm{J}$ Cardiothorac Surg 2010;37:573-5. 